\section{Taxonomy of Haemophilus vaginalis}

The numerous authors who have reported the isolation of 'Haemophilus vaginalis' from cases of vaginitis, or of non-specific urethritis in men, have not succeeded in determining its $X$ and $V$ requirements; thus its taxonomic position is uncertain. We have therefore examined six strains of $H$. vaginalis -two from C. D. Dukes, who with Gardner first described this species ${ }^{1}$, and four from P. N. Edmunds ${ }^{2}$.

It was found that these strains, inoculated on fresh blood agar ${ }^{2}$ and incubated microærophilically with increased carbon dioxide at $37^{\circ} \mathrm{C}$., grow witbin three days as pinpoint hæmolytic colonies of Gram-negative rods. If, however, films are made after 18-24 hr. from hæmolytic zones in which no colonies are visible, the rods are found to be Gram-positive, with an arrangement suggestive of corynebacteria.

Moreover, all six strains grow comparatively copiously on nutrient media with a high serum content. On Roux inspissated serum, single colonies reach a diameter of $5 \mathrm{~mm}$. after incubation for 7 days. All strains grown on Roux serum slopes are constantly Gram-positive, the majority of rods showing welldeveloped polar granules and some clubbing. They are catalase-negative and do not grow on a 0.04 per cent potassium tellurite medium suitable for the growth of $C$. diphtheriae ${ }^{3}$.

Some of these characteristics are shown, according to Bergey's Manual of Determinative Bacteriology ${ }^{4}$, by C. parvum. Two authentic strains of this species were obtained and compared with the six cultures of ' $H$. vaginalis'.

The following constant differences were found on repeated examination. $C$. parvum stains Grampositive uniformly at all stages of growth, and is catalase-positive. Unlike ' $H$. vaginalis', it ferments sorbitol, adonitol and mannose; on the other hand, ' $H$. vaginalis' strains ferment maltose, dextrin and starch, which are not attacked by $C$. parvum. Both species ferment glucose, lævulose and xylose. There is therefore little doubt that these ' $H$. vaginalis' strains are not identical with $C$. parvum but are a species of Corynebacterium not previously described, for which the name Corynebacterium vaginale is suggested.

K. ZINNEMANN

G. C. TURner

Department of Bacteriology, School of Medicine, Leeds, 2.

${ }^{1}$ Gardner, H. L., and Dukes, C. D., Amer. J. Obst. Gynec., 69, 962 (1955)

Edmunds, P. N., J. Path. Bact, 79, 273; 80, 325 (1960).

${ }^{3}$ Johnstone, K. I, and Zinnemann, K., J. Path. Bact., 55, 53 (1943).

4Bergey's Manual of Determinative Bacteriology, seventh ed., 588 Bailière, Tindall and Cox, Ltd., London, 1957).

\section{GENETICS}

\section{Fertility and Chromosome Pairing in Autotetraploid Rye}

IT is generally accepted that the fertility of autotetraploids depends in part on the types and distributions of chromosome associations at meiosis. On this basis selection for heritable change in the distributions of the associations should be effective in improving fertility. There is, however, little experimental evidence to confirm this ${ }^{1-3}$. On the contrary the evidence of Morrison ${ }^{4}$ and of Morrison and Rajhathy ${ }^{5,6}$ indicates that selection would be in- effective. They find no evidence either for heritable variation in the pattern of chromosome association at meiosis or for its effect on fertility.

These results are surprising. There are at least two good reasons for expecting heritable variation in the chromosome association pattern: (1) Theoretically, the types and frequencies of the associations: quadrivalent, trivalent plus univalent, bivalent pair, bivalent plus two univalents and four univalents, must depend partly on chiasma frequency ${ }^{7}$. (2) Chiasma frequencies are genotypically controlled . $^{8}$.

That both factors are relevant and operate to control the fertility of autotetraploids is in fact established by our own investigations on rye. The results which follow here are from induced autotetraploids of two $\boldsymbol{F}_{2}$ families derived from crossing three diploid inbred rye lines in pairs. Firstly, the range of chiasma frequencies found in these and other $F_{2}$ families indicates segregation of genes controlling chiasma frequencies. Secondly, when quadrivalent and univalent frequencies are plotted against the chiasma frequencies of the $F_{2}$ plants, as in Fig. $1 A$ and $B$, it will be seen that the distributions of the various chromosome configurations are dependent on the chiasma frequencies. In each case the regressions are significant. The frequencies of the other associations show exactly the same dependence on chiasma frequencies. Clearly the adjustment of chromosome association frequency is a consequence of change in
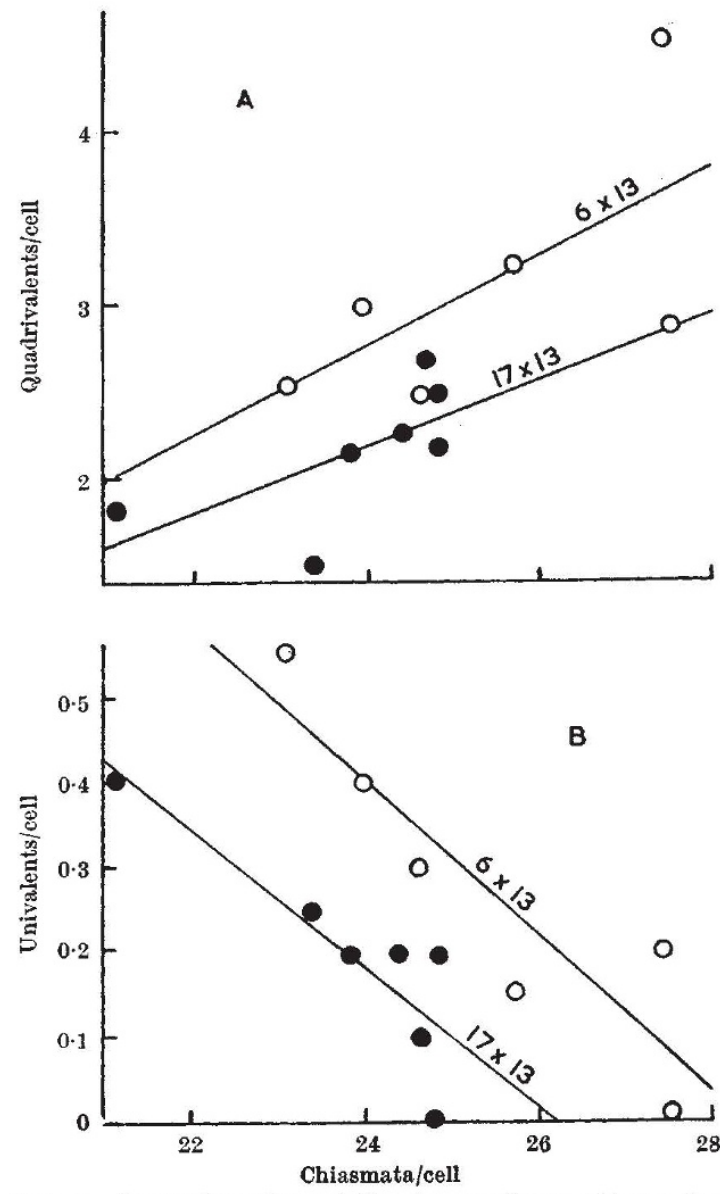

Fig. 1. Regression of association frequencies on chiasma frequencies in the two $F_{2}$ familles. $A$, Quadrivalent distribution; $B$, univalent distribution calculated from the frequencies of the 